\title{
Using E-learning in the digital transformation of an Italian Public Administration
}

\author{
Milena Casagranda, Luigi Colazzo Andrea Molinari
}

\begin{abstract}
This paper presents a case study of using a Learning Management System and SCORM-based material in order to introduce companies to innovative practices, specifically the use of the Digital Signature and the Certified Electronic email. These two innovations, together with others, have recently become mandatory when enterprises will have to interact with the Italian Public Administration. This is an important push towards innovation through dematerialization processes, but it involves millions of citizens and companies. An enormous training effort is therefore needed to allow the Italian economic system to be aligned with these innovations. The latest example is the electronic invoice, that is mandatory in B2G since $31^{\text {st }}$ of march 2015: no payments will be made by the Italian Public Administration to Italian companies if the invoice will not be created as an electronically-signed, XML based file. This paper presents our experience in the design, creation and delivery of distance learning material designed with the Chamber of Commerce of Trento, through a description of the project started in 2011 and involving the dematerialization and digitalization of relations between businesses and the Public Administration.

Keywords- e-learning, Public Administration, dematerialization, learning objects
\end{abstract}

\section{INTRODUCTION}

The digital agenda of European governments, especially the one related with Horizon 2020, is particularly compelling under many perspectives. Surely, it is increasing significantly the impact of ICTs on the Public Administration's processes, thus affecting in turn on all European citizens and enterprises. Italy has been, at least from a legal perspective, one of the nations that has deeply absorbed this approach, considering that the dematerialization process that is the basis of $\mathrm{H} 2020$, has already started many years ago.

The main step of this modernization (not always implemented as expected), was in 2005, when several radical changes have been introduced by the Digital Administration Code (CAD) in Italian Public Administrations (PAs). The objective was changing PAs' processes through dematerialization and ICT innovation. Consequently, most of the Italian citizens and organizations that interacted with Italian PAs will see important changes in the processes, not only because of the constant interaction with the PA itself for different reasons (from tax payments to requests). This

Milena Casagranda, Luigi Colazzo

Department of Industrial Engineering

University of Trento

Via Sommarive, 2 - Trento

Andrea Molinari

Department of Industrial Engineering / University of Trento

Dept. of Industrial Engineering and Management / Lappeenranta University of Technology

Skinnarilankatu 3453850 Lappeenranta, Finland revolution in Italian society will influence also the way citizens and companies will exchange information in the future.

Subsequently integrated and amended, the CAD is now operational, and since December 2012, a new version with important novelties has been emanated. Despite its name, CAD applies to both private and public bodies, and it states a completely new scenario for the usage of ICT, in such a way that PAs can be more efficient and reactive in the relationship with their stakeholders. Among the pillars on which the digitalization is based, two are particularly relevant: a) use of the electronic signature for signing electronic documents; b) use of certified emails;

These two services have created many reactions, mainly in terms of resistance to change, from citizens (that were not obliged to have them) but mainly from companies. Recent data published by the Italian government show a good start of diffusion (presented in the following tables 1 and 2), but a following stop.

\begin{tabular}{|c|r|r|r|}
\hline YEAR & Tot.Domains & Tot.Mailboxes & Tot.Messages \\
\hline 2007 & 42.369 & 618.165 & 116.376 .864 \\
\hline 2008 & 111.244 & 1.147 .208 & 218.477 .050 \\
\hline 2009 & 295.220 & 3.943 .160 & 253.098 .716 \\
\hline 2010 & 578.258 & 11.518 .079 & 327.476 .760 \\
\hline 2011 & 840.404 & 17.797 .879 & 324.125 .539 \\
\hline 2012 & 1.164 .829 & 28.297 .727 & 459.662 .512 \\
\hline Grand Total & 3.032 .324 & $\mathbf{6 3 . 3 2 2 . 2 1 8}$ & $\mathbf{1 . 6 9 9 . 2 1 7 . 4 4 1}$ \\
\hline
\end{tabular}

Table 1: the diffusion of PEC domains, mailboxes and messages in last six years (DIGITPA, 2013)

\begin{tabular}{|l|r|r|r|}
\hline YEAR & Tot.Domains & Tot.Mailboxes & Tot.Messages \\
\hline 2007 & $100 \%$ & $100 \%$ & $100 \%$ \\
\hline 2008 & $263 \%$ & $186 \%$ & $188 \%$ \\
\hline 2009 & $697 \%$ & $638 \%$ & $217 \%$ \\
\hline 2010 & $1365 \%$ & $1863 \%$ & $281 \%$ \\
\hline 2011 & $1984 \%$ & $2879 \%$ & $279 \%$ \\
\hline 2012 & $2749 \%$ & $4578 \%$ & $395 \%$ \\
\hline
\end{tabular}

Table 2: previous data in percentage in last six years (DIGITPA, 2013) 
The problem for the Italian PAs is not in the lack of people able to optimize and improve processes. The lack is in the capabilities of Italian PAs and citizens to metabolize the innovations that digitization and dematerialization offer, because of an endemic resistance to changes. Table 3 presents the situation of PEC adoption in some of the most "efficient" Italian provinces, where the Autonomous Province of Trento (Provincia Autonoma di Trento - PAT) is in the top positions (source: DIGITPA, 2013)

\begin{tabular}{|c|c|c|c|}
\hline Chantert at Cammetes & N. Of tumpaties & withive & s \\
\hline Cuneos & 24.843 & 22.569 & $91 \%$ \\
\hline Sondrio & 6.543 & 5.920 & $90 \%$ \\
\hline Boltano: & 21.494 & 19.751 & $90 \%$ \\
\hline Forii & 19.834 & 17.526 & $88 \%$ \\
\hline Trento & 27.297 & 19.632 & $88 \%$ \\
\hline Pordenone & 12.054 & 10.544 & $87 \%$ \\
\hline Prato & 16.644 & 14.461 & $87 \%$ \\
\hline Bereamo & 47.636 & 41.036 & $86 \%$ \\
\hline Bdiluno: & 6.992 & 6.023 & $86 \%$ \\
\hline Mantova & 17.649 & 15,170 & $86 \%$ \\
\hline
\end{tabular}

Table 3: adoption of Italian certified emails among large corporations and SME

Over a national average of $74 \%$ of adoption of certified email, the Autonomous Province of Trento has the $88 \%$ of organizations that formally adopted this tool.

Another interesting element of analysis regards the situation of the traffic of certified email during the last six years (source: DIGITPA, 2013). This clearly shows an increasing adoption of CAD that could in turn indicate that few organizations and individuals are adopting CAD rules, but they are using in progressive and extensive ways. Interesting to note that from 2007, PEC domains and mailboxes have increased respectively of 27 and 45 times but the number of PEC messages have increased of just four times. From the data provided by accredited certifiers, from May 2014 to July 2015 we see an increase of more than $50 \%$ of active digital signature certificates: in May 2014 were 5,319,800 certificates, in July 2015 there were 8,104,615 valid certificates. An estimated $75 \%$ of active digital signature certificates are predominantly related with systems of remote signature, i.e., using the most advanced form of digital signature available today for PAs.

This is a clear effect of the compulsoriness for CAD prescriptions, but it is not representing an intimate and convinced adoption. Italy has now the legal framework, and ICT provides the technological tools for a take-off in the adoption of CAD prescriptions. The missing link now is a pervasive training initiative devoted to individual users and organizations about the tools introduced by CAD. The promotion of this cultural growth of Italian citizens and organizations is clearly in charge of the PAs. Besides, if we look at companies, the situation radically changes (Table 4).

As a last element, since March 2015, any invoice sent to Italian PA must be an "electronic invoice" following a precise XML schema and sent through specific certified channels. Many changes are implied (organizational, technological, ruling) and implementation is certainly not instantaneous, but the whole impact on the Italian society is very relevant.
Therefore, the Italian PA is moving in this direction, where digital signature and electronic certified emails have already made a relevant progress in terms of implementation, while the other two themes are taking off.

\begin{tabular}{|c|c|c|c|}
\hline Whamber of Conntheste & 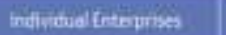 & Wethece & $\mathrm{s}$ \\
\hline 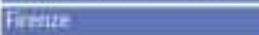 & 53.909 & 2.399 & 48 \\
\hline Praton & 16.506 & 704 & $4 \%$ \\
\hline Herno: & 18.458 & 781 & $45 \%$ \\
\hline Diminis: & 19.944 & 834 & 45 \\
\hline feramo: & 21.643 & 853 & $4 \mathrm{~N}$ \\
\hline arotone & 12.276 & 482 & 45\% \\
\hline Avironai & 26.885 & 1.047 & 48 \\
\hline Fistreras & 18.227 & 699 & 496 \\
\hline Fancia: & 17.455 & 664 & 4S \\
\hline$=$ & $-\ldots$ & ....m. & $\ldots .$. \\
\hline 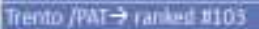 & 20.023 & 359 & 15 \\
\hline
\end{tabular}

Table 4: adoption of Italian certified emails among individual enterprises

The technical problems related with such an innovation have clearly emerged during the last years: the one that is of interest in this paper, and from our point of view, the most relevant problem relates with the training of different categories of users that will have to deal with XML files, digital signature, certificates etc. What we observed is that, even if the process to follow is simple, there are relevant technical obstacles that avoid companies, especially SMEs, to adopt these innovations.

According to a sample of 70 SMEs that the Chamber of Commerce of Trento interviewed through a qualitative questionnaire, the most evident difficulties in adopting these innovations are the following:

- managing a computer in an autonomous way

- $\quad$ creating a PDF file (to be signed afterwards)

- $\quad$ using a smartcard to sign a file

- creating a file in the XML format required by the Italian PA

- checking if the file created complies with the requested format

As you can see, the first problem is a general computer skills problem. In our Province, many investments have been done in training on this subject, both in presence and online, trying to raise the level of computer skills in entrepreneurs and their workers, but according to this small sample (and according to our day-by-day experience on the field), this is still a huge problem. Especially a mountain region like our region sees many SMEs in the agricultural and touristic industry, with evident problems in being autonomous in computers' management.

Considering that, in the future, administrative procedures will be managed exclusively through electronic transmission; we can imagine the extension of this problem and its impact on Italian society. Many different temporary solutions appeared to solve this issue: professional associations are providing to affiliates free invoicing services (but for a limited amount of 
invoices) and some free software appeared on the market (even if their usability is not perfect, especially for the cited category of users). According to the fact that interaction with citizens and businesses will increase constantly, it is clear that some stable and effective remedies to this situation must be found rather quickly, also considering the number of subjects involved. Not only the citizens/companies sides are affected: these elements radically change the scenario for ICT usage inside organizations, in particular in PAs.

Beside a design, realization and re-engineering of information systems and applications supporting such new modalities, reengineering of business processes and procedures are needed. Nevertheless, public servants perform their working processes without technologies. In case of inefficiencies, they are requested to contribute with their knowledge while applying CAD prescriptions. These people are normally experts in their field, but probably not so experts in the specific domain of the CAD. The main expertise is hidden and not shared, formalized or clarified: from tacit knowledge, PAs will have to extract this information and transform it into explicit knowledge. Finally, the Italian legislation stimulates the sharing and reuse of any educational resource produced by/for the PAs, in order to optimize investments and maximize uniformity of view about the topics.

In order to face this situation, an obvious need of training for millions of citizens, public and private employees or organizations is needed. Often, companies are reluctant to adopt innovative solutions, stopped by the cliché of new technologies capable only to create complex and critical processes, especially if this innovation stimulus comes from the PA. The question now is no longer in these terms: companies have to adapt to what the CAD indirectly requires them, or they risk not only to stay out of a process of modernization that paradoxically involves and is generated by the PA, but that is likely to have consequences in terms of fines and sanctions. The processes of dematerializing documents is irreversible, also because the advantages are becoming clear to everybody. In terms of training, the central administration provided support to Italian PAs through a set of informative initiatives. To support businesses and public administrations in the transition to e-invoicing, in particular in the period closer to the deadline of 31 March 2015, the various parties involved have organized a series of initiatives. These range from support services to direct coaching dedicated to both businesses and public administrations, like for example a group of "digital Champions" that have been addressed to local administrations in order to help in the implementation of the CAD.

Another reference point of the relationship between CAD and business is certainly the Chamber of Commerce, with which all the Italian companies have different kind and level of relations. This is therefore one of the best places to intercept needs and problems from companies, and provide them with adequate answers. Having a long tradition in e-learning projects, in 2011 we set a working group together with the Chamber of Commerce of Trento, in order to use learning objects and e-learning principles to reach the highest part of companies and to support them in this quick and central change. When the state of maturation of the CAD was clear, we decided to create e-learning materials to help companies to improve certain processes without distorting them, bringing advantages in terms of speed, efficiency and cost containment through the application of the dictates of CAD.

The Chamber of Commerce of Trento have used our elearning and virtual communities' platform since 2007, and the project aimed at raising awareness on the topic: sending printed material and newsletters, organizing dedicated events, publishing articles in newspapers or on magazines with dedicated spaces, opening specific spaces in the website, launching various initiatives and seminars. All these efforts have reached, over two years, about 300 companies in our region. However, it was clear the impracticability of reaching a larger number of organizations (approx. 55.000 organizations subject to the new law) on schedule for the CAD deadline. Thus, e-learning has naturally become the mean to achieve:

- $\quad$ low cost and at appropriate times;

- broader audience [3] [6] [8].

In this article we present the experiments carried out by the research group of the Laboratory of Maieutics of the University of Trento, the Chamber of Commerce of Trento and the Province of Trento, for the realization of learning objects [4] [12] available to companies of Trentino and accessible through the e-learning platform developed by our group.

\section{LEARNING SOLUTIONS FOR PUBLIC INSTITUTIONS}

Looking at the results presented in the European Digital Agenda (EDA) Scoreboard 2012, the needs of e-government in Europe seem very clear, keeping into consideration all the stakeholders involved. The European Digital Agenda (EDA) has the target of increasing regular Internet use to $75 \%$ of the population. The confident projections of last year's scoreboard have been reviewed -- the 75\% target will be probably reached in 2014 and not in 2013, although still ahead of the EDA target year of 2015 .

Though the usage of e-Government by citizens is stable at $41 \%$ with some significant progress in smaller countries, the main reasons of resistance for non-use of online public services by citizens are:
a) lack of need;
b) lack of trust;
c) lack of skills.

Nevertheless, digital agenda is pushing towards the adoption of ICT-related procedures and process re-engineering. Citizens and firms will steadily increase to require eGovernment services (usage by firms has increased steadily from $76 \%$ in 2010 to $84 \%$ in 2011), and civil servants will be forced to adopt ICT not only for their ordinary work, but also to improve their processes according to ICT availability. This is a great effort, as the incomplete digitalization of public services is an important barrier to an increasing e-Government take-up.

The initiative "EPSA Trends in Practice-Driving Public Sector Excellence to Shape Europe for 2020" demonstrated the need of integration, contacts and networks to be established among those PAs able to showcase their achievements in terms of a) modernization, b) innovation c) smart solutions facing 
with budget constraints, increasing demands from citizens and service delivery improvement. The milestone for this is the availability of the EPSA learning platform.

Some market research demonstrated that almost $90 \%$ of public sector Learning Departments plan to increase the use of e-learning technologies in order to meet cost reduction targets set in the Comprehensive Spending Review (CSR) ${ }^{1}$. While at the beginning of 2009 only 50\% of Learning Development managers expected to increase their use of e-learning, $88 \%$ currently anticipate an increase, and more trainers expect to use collaborative learning techniques. In this sense, the current economic period of austerity is clearly having a deep impact on these considerations, with no much distinction between private and public sector.

The examples reported in market research are very clear in this sense. The City of Edinburgh Council Interactive Learning (CECiL) started four years ago providing online learning for all employees, reducing training costs by more than $£ 800,000$. The conditions under which to provide these savings are well known: high volume training to be delivered in a short period of time.

Learning solutions for public sector have been promoted in the past in many different ways, with results that did not meet expectations. During recession periods like the one we are living, Technology Enhanced Learning (TEL) has been indicated as a panacea for future learning, a sort of "killer" of training in a classroom. Similarly, many times in its history TEL has not been living up to the hype. The public sector expects to use e-learning to improve the level of service delivered to organizations despite budget cuts. This seducing metaphor attracted the public sector, fitting well with the push towards e-government.

Notwithstanding, reality showed a different picture. TEL has a lot of researches and application studies in the public sector if we consider as "public sector" the educational institutions from primary schools to master degrees. However, if we exclude this relevant part of use cases, the traditional Public Administrations have not been investigated as possible application field of TEL-based training programs. There are many examples of training employees with TEL that seem to be pushed by the idea of cost saving, or by the idea of substituting missing educational paths (as for example, requalification of civil servants that have no degree in their curriculum).

Most of use cases are concentrated in the period 2005-2010 [14],[15],[16]. Different experiences coming from different countries, but a non-unique vision of the specificity of public sector. So, in terms of state-of-the-art of TEL in public sector, the situation is not clear like in the private sector, or in the traditional educational system. Many studies have concentrated their attention to the application of TEL to institutional training, supporting traditional training with technologies, methodologies and tools. On the contrary, little attention has been devoted to TEL inside Public Administrations and their employees, with their specificity and needs.

\footnotetext{
${ }^{1}$ http://www.brightwave.co.uk/
}

Public Administrations have been involved, together with their employees, in TEL applications mainly for lifelong learning projects, considering the public servants as persons that will stay for a long time in the same workplace, and therefore an interesting case study for lifelong learning researches and applications. Nevertheless, even if we exclude educational institutions from the application field, the public sector is a place where all theories, methodologies and tools studied and implemented in TEL could be profitably applied. Most of the new approaches and tendencies in TEL, like storytelling, MOOCs, gamification etc. could be applied to the large ecosystem of public stakeholders. Public Administrations are particularly interested in TEL:

- because they consider e-learning and web-based resources as fundamental elements of their training processes;

- because of TEL capabilities to deliver contents over the Internet anytime and anywhere at competitive costs.

Nevertheless, most of these well-known problems have now been overcome: it therefore seems that the hesitant progress of TEL - always on the point of spreading extensively and then for some reason never really succeeding - should not have to continue any longer, given the disappearance of many technological barriers. Other obstacles have been cleared, i.e., standardization and reuse of learning material.

Almost any public institution has at least considered using one of the different available approaches (blended or full online). Tools available today can guarantee the service level required from Public Administrations: platforms like Learning Management Systems (LMS), technologies like videoconference, standards for learning metadata or objects like SCORM or LOM [11], LTSC [12].

Another effect of the maturity of TEL for the public sector regards the large amount of educational material that has been produced and that is now available under various forms. Various institutions have created several Learning Objects (LOs) mostly freely available. These elements, combined with reusability, cost reduction, time optimization and a more modern view of the PA, have contributed to raise expectations in public sector about TEL. In terms of factors that influence TEL adoption inside PAs, some studies conducted in Pas indicate that civil servants' opinion regarding e-learning was significantly influenced by their satisfaction, and this is in turn affected by five different aspects: a) job relevance; b) expectation confirmation; c) perceived ease of use; d) perceived usefulness; e) computer self-efficacy. Other studies show that adult learners perceive positively the effectiveness of e-learning in the workplace.

\section{CREATING LEARNING OBJECTS FOR THE ITALIAN PA}

Beside a design and realization of applications supporting such new modalities, a deep learning intervention must be performed in order to take advantage of the opportunities created by the CAD. First of all, new rules, new systems and new procedures must be acquired by all civil servants acting inside Pas. Secondly, re-engineering of business processes and procedures will be needed. 
Since 1998, our research group developed a long experience in e-learning applications, specifically in Public Administration. We currently are delivering e-learning initiatives with many public and private partners, among which the Autonomous Province of Trento ( 12.000 employees), Trento Chamber of Commerce $(\sim 55.000$ individuals and small/medium Enterprise' users $)$ Trentino Development Agency $\quad(\sim 1.000$ users/companies), the Academy of Commerce and Tourism ( 1.000 users/companies) and of course the University of Trento ( 15.000 users). Through our experience of e-learning in PAs, we have proven that excellent results could be obtained not only using e-learning as a substitute of traditional classroom, but also involving and motivating the public servants directly in the creation of the learning objects. These results can be obtained if elements are available during the creation of the educational path:

a) a common methodology for gathering, formalizing and distributing requisites, thus avoiding their uncontrolled production;

b) a different approach for traditional F2F interaction with teachers/experts, less formal and "boring" compared to PowerPoint-like presentations;

c) a virtual place with a strong collaborative connotation where to share ideas and results with other colleagues, in order to compare different views and interpretation of the process, especially from a legal point of view;

d) the availability of consultants on legal topics able to provide straight-to-the-point advices: a teacher more than a consultant, is needed;

e) a way to see activities recognized and rewarded, at least in terms of reputation, a formal way to recognize the work done in e-learning material production.

Many learning packages and training initiatives have been started after the advent of the CAD but no tangible results are visible yet. As a direct experience, we decided to specifically develop e-learning SCORM packages regarding all the CAD topics. We have produced 14 hours of learning objects explaining in details the two tools that are mandatory for companies today, i.e., digital signature and certified email. We launched this initiative in 2011 together with PAT and involving various professional associations.

In PAT over approx. 55.000 enterprises (public and private large corporations, SME, individual companies) approximately 700 participated to this joint initiative PAT-Chamber of Commerce-University of Trento with the fruition of e-learning material completely free-of-charge. In order to interpret this data correctly, we considered how most of public servants and professional associations used our platform for e-learning activities.

After this, we tried to choose a different approach: in the last months of 2012, we experimented an approach to elearning creation, for some associations related to the local Chamber of commerce, regarding three processes:

- permits to the opening of new hotels in touristic areas;
- registration of a new company to the Local Registry of Enterprises;

- cancellation of a company from the Local Registry of Enterprises.

This time, our experts created the material, but with a deep interaction with the public servants in charge of the above processes. Preliminary results are clearly showing that this change of gear produced a significant appreciation from endusers. After testing other methods like the creation of learning objects by academic experts, it is clear that learning objects created by internal people with a high reputation, are by far more appreciated and trusted.

We are therefore injecting a new paradigm of delivering training to public servants, citizens and companies by changing the producer and the methods of production, share and use of the e-learning material. Nevertheless, it is clear that the level of complexity in processes' re-engineering caused by CAD is manageable by these "prosumers" when supported on purpose by experts that act more as consultants than teachers.

The biggest problem has occurred in the design phase, when we turned materials provided by experts into learning objects, both in terms of effort estimation of our development team and the Chamber of Commerce of Trento, and for the quantification of the rewarding to authors of materials and learning objects. This is the typical case of industrial production of learning objects where a "teacher" should be paid for an amount by far superior to the total duration of the learning objects produced. We solved this issue by adopting the cost for creation of online learning objects presented in [5] [10].

The two themes "Digital Signature" and "Certified Electronic Mail" were treated separately, to provide different ways to adapt training needs to pre-existing knowledge or skills already present in the organization. For each item, we provided three distinct levels of learning, adaptable to the needs and to specific questions. The material is in fact accessible both by following a sequential approach and an application-driven approach that allows the user to immediately identify topics of interest.

The levels of organization of content are three:

1) informatory level, aimed at disseminating knowledge on the issues, and then answering the questions with respect to acting professionally. This is obtained by clearly expressing the benefits and points of attention resulting from its use, as well as a stimulus in the questions raised during the training sessions and telephone follow-up triggered by the Chamber of Commerce on a sample of 50 firms;

2) "use" level, designed to provide practical tools for the two topics, with the use of tutorials that guide you systematically in the activation of the instrument, in its use, in the verification of correctness of the operations. At this level, we used recorded sessions of interaction with the software tools to digitally sign and send certified emails;

3) "deep" level, devoted to users or potential users of the two instruments who wish to become more aware of the 
implications deriving from their usage, particularly in normative terms. In fact, the normative has been reduced in scope during the design of the learning objects described above.

The proposed material in the three levels described above, was preceded by an introductory video that outlined the main concepts of reference tools, in order to encourage the vision of successive packets, but also provide some aspects and useful information for a first orientation for those who are not "familiar" with the topics covered. The course material was not produced in pure SCORM [11], [12], but it is designed and arranged so as to be subsequently transformed into SCORM when the e-learning platform of the Chamber of Commerce will be equipped with a SCORM player suitable to hold the numbers of expected users (potentially 22,000 companies in the coming years).

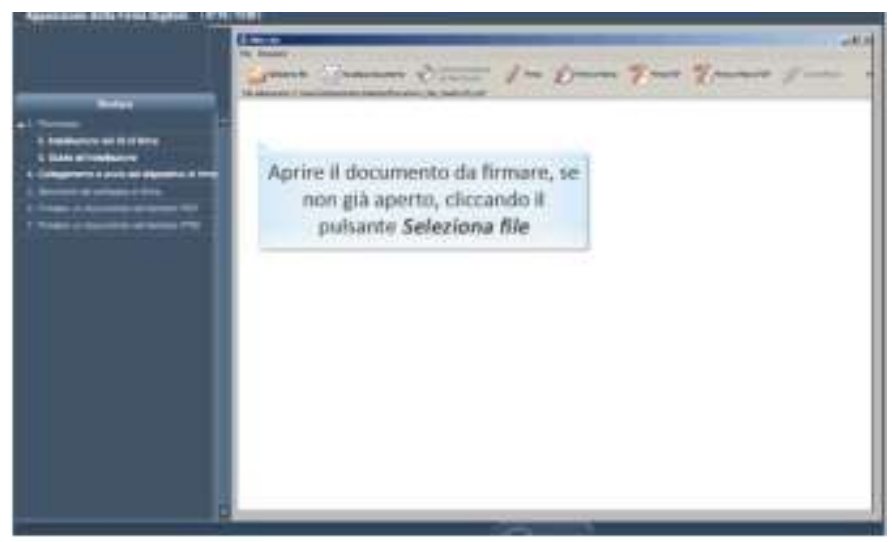

Fig. 1: example of educational path on digital signature

Our main evidences for the design and implementation of this e-learning educational project are the following, according to the specific conditions explained in previous chapters:

a) micro-design of contents, and especially length of video, is fundamental for a successful e-learning multimedia material. Detailed scheduling of every single items in a very fine-grained way has been not only required, but helped also the domain expert to better clarify contents and duration of the learning objects

b) This allowed a greater modularity of contents, especially considering that the regulations behind the course materials were subject to frequent updates;

b) we involved users in a virtual community limited to members and key stakeholders, in order to increase the quality of the results. In this sense, the logic of massive, open courses seemed not to be the best option. Motivations for participants were very concrete, not just a personal educational need;

c) we used a platform that is structurally designed to implement the idea of virtual community, rather than simply manage a classroom or a training event [7]. This element allowed us to provide services that are typical of self-organized communities, rather than "classrooms". For example, (simple) project management tools, certification paths, public tender mechanisms (like electing committee's members); d) we increased the remuneration of the actors involved (teachers, content experts, e-tutor) using a cost model specifically designed for e-learning by increasing the evaluation of the time spent in producing learning objects effort. Teachers have been paid on a new e-learning cost model, thus guaranteeing them an adequate revenue for the loss of chances of future courses;

e) we enabled a lifelong learning context, designing a path that includes the migration of many of the training activities, information and update of the Chamber of Commerce of Trento towards these tools. This demonstrated the benefits always professed by e-learning researches, but which now seems even more indispensable for any Public Administration involved in the digital modernization.

\section{CONCLUSIONS}

Up to now, more than 700 companies have benefited from the material made available on the platform and have gradually reported needs compared to other types of content available. For this reason, from 2012, the Chamber of Commerce has decided to make available some specific topics to other communities, specifically related to the aspects that gathered more questions or more errors. The Chamber of Commerce, due to the very positive feedbacks received both on the approach and on the contents, has decided to invest in elearning for the creation of video lessons related to the common practice of "balance sheet management" and "Business Register". Both courses have been released and delivered to specialized companies. The Chamber of Commerce of Trento has also involved in 2014 the Chamber of Commerce of Bolzano, in order to share and reuse the material produced for blended learning, which could encourage companies from adjacent areas to participate.

We are conducting further actions to raise awareness of companies, including through the evaluation of a partnership with the Association of Public Accountants that are a reference point for many small and medium entrepreneurs respect to electronic invoice.

\section{REFERENCES}

[1] Adelsberger H. (2003), "The Essen model: a step towards a standard learning process," http://citeseer.ist.psu.edu/515384.html, 2003.

[2] Boyd D. (2006), Friends, friendsters and mySpace Top 8: writing community into being on social network sites. First Monday 11(2), December.

[3] Stamatios A., Tsihrintzis G.. "Education and Assessment of Civil Employees in e-Government: The Case of a Moodle Based Platform." interaction 4: 5 .

[4] Brooks, C. and McCalla G. (2006), Towards flexible learning object metadata. International Journal of Continuing Engineering Education and Life-Long Learning, 2006. 16(No.1/2): pp. 50 - 63.

[5] Casagranda M., Colazzo L., Molinari A. (2013), Estimating the effort in the development of Distance Learning paths, ICE-B - 10th International Joint Conference on e-Business and Telecommunications, Reykiavik (Iceland), 29-31 Jul 2013

[6] Colazzo, L., Molinari, A., \& Villa, N. (2011). Formal and informal lifelong learning in a virtual communities platform. Lecture Notes in Computer Science including subseries Lecture Notes in Artificial Intelligence and Lecture Notes in Bioinformatics.(2011), Volume: 6537 LNCS, Pages: 291-300

[7] Colazzo, L.; Molinari, A.; Villa, N.(2009), "Collaboration vs. Participation: The Role of Virtual Communities in a Web 2.0 World," 
Proc. of the Third Intl. Conf. on Advances in Mechanical and Automation Engineering - MAE 2015.

Copyright (C) Institute of Research Engineers and Doctors, USA .All rights reserved.

ISBN: 978-1-63248-080-4 doi: 10.15224/ 978-1-63248-080-4-72

Education Technology and Computer,. ICETC '09. International Conference on , vol., no., pp.321-325, 17-20 April 2009

[8] Moore, M. G \& Kearsley, G. (2012). Distance education: A systems view of online learning. Belmont, CA: Wadsworth, Cengage Learning

[9] Rennie F., Morrison T.. E-learning and social networking handbook: Resources for higher education. Routledge, 2012.

[10] Casagranda M., Colazzo L., Molinari A. (2010), E-learning as an opportunity for the public administration: results and evolution of a learning model. In International Journal of Teaching and Case Studies, Vol. 2, N. 3/4, 2010, ISSN (Online): 1749-916X - ISSN (Print): 17499151, InterScience

[11] LOM: IEEE Learning Object Metadata standard http://ltsc.ieee.org/wg12/

[12] LTSC. (2011) IEEE Standard for Learning Object Metadata, 1484.12.12002, IEEE LTSC, 2002.
[13] Rheingold H.(2000) The Virtual Community: Homesteading on the Electronic Frontier, The MIT Press; revised edition edition (November 1, 2000)

[14] Ifrim, V. M., Stănescu, i. A., \& stefan, a. (2010). Smart e-learning for sustainable performance in public organisations. In Conference proceedings of" eLearning and Software for Education"(eLSE) (No. 01, pp. 187-194).

[15] Sannia, M., Ercoli, G., \& Leo, T. (2009). Evaluation of Virtual Learning Environment for the Professional Training in Public Administration. International Journal of Advanced Corporate Learning (iJAC), 2(1), 5055.

[16] Nisar, T. M. (2004). E-learning in public organizations. Public Personnel Management, 33(1), 79-88. 